\title{
Front Matter: Volume 8832
}

, "Front Matter: Volume 8832," Proc. SPIE 8832, The Nature of Light: What are Photons? V, 883201 (7 October 2013); doi: 10.1117/12.2045843

SPIE Event: SPIE Optical Engineering + Applications, 2013, San Diego, California, SPIE. United States 


\section{PROCEEDINGS OF SPIE}

\section{The Nature of Light: What are Photons? V}

Chandrasekhar Roychoudhuri

Al F. Kracklauer

Hans De Raedt

Editors

26-29 August 2013

San Diego, California, United States

Sponsored and Published by

SPIE 
The papers included in this volume were part of the technical conference cited on the cover and title page. Papers were selected and subject to review by the editors and conference program committee. Some conference presentations may not be available for publication. The papers published in these proceedings reflect the work and thoughts of the authors and are published herein as submitted. The publisher is not responsible for the validity of the information or for any outcomes resulting from reliance thereon.

Please use the following format to cite material from this book:

Author(s), "Title of Paper," in The Nature of Light: What are Photons? V, edited by

Chandrasekhar Roychoudhuri, Al F. Kracklauer, Hans De Raedt, Proceedings of SPIE Vol. 8832 (SPIE, Bellingham, WA, 2013) Article CID Number.

ISSN: 0277-786X

ISBN: 9780819496829

Published by

SPIE

P.O. Box 10, Bellingham, Washington 98227-0010 USA

Telephone +1 3606763290 (Pacific Time) · Fax +1 3606471445

SPIE.org

Copyright (C) 2013, Society of Photo-Optical Instrumentation Engineers.

Copying of material in this book for internal or personal use, or for the internal or personal use of specific clients, beyond the fair use provisions granted by the U.S. Copyright Law is authorized by SPIE subject to payment of copying fees. The Transactional Reporting Service base fee for this volume is $\$ 18.00$ per article (or portion thereof), which should be paid directly to the Copyright Clearance Center (CCC), 222 Rosewood Drive, Danvers, MA 01923. Payment may also be made electronically through CCC Online at copyright.com. Other copying for republication, resale, advertising or promotion, or any form of systematic or multiple reproduction of any material in this book is prohibited except with permission in writing from the publisher. The CCC fee code is 0277-786X/13/\$18.00.

Printed in the United States of America.

Publication of record for individual papers is online in the SPIE Digital Library.

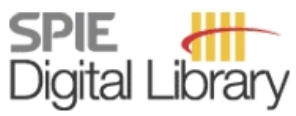

SPIEDigitalLibrary.org

Paper Numbering: Proceedings of SPIE follow an e-First publication model, with papers published first online and then in print and on CD-ROM. Papers are published as they are submitted and meet publication criteria. A unique, consistent, permanent citation identifier (CID) number is assigned to each article at the time of the first publication. Utilization of CIDs allows articles to be fully citable as soon as they are published online, and connects the same identifier to all online, print, and electronic versions of the publication. SPIE uses a six-digit CID article numbering system in which:

- The first four digits correspond to the SPIE volume number.

- The last two digits indicate publication order within the volume using a Base 36 numbering

system employing both numerals and letters. These two-number sets start with 00, 01, 02, 03, 04, $05,06,07,08,09,0 A, 0 B \ldots$. 0Z, followed by 10-1Z, 20-2Z, etc.

The CID Number appears on each page of the manuscript. The complete citation is used on the first page, and an abbreviated version on subsequent pages. Numbers in the index correspond to the last two digits of the six-digit CID Number. 


\section{Contents}

ix Conference Committee

xi Introduction

\section{KEYNOTE SESSION}

883202 The nature of light: what are photons? [8829-100]

C. Mead, California Institute of Technology (United States)

\section{EXPERIMENTS AND OPTICAL TECHNOLOGIES}

883203 A method of comparing the speed of starlight and the speed of light from a terrestrial source [8832-2]

J. Wu, National Taiwan Univ. (Taiwan); S.-T. Chang, Instrument Technology Research Ctr. (Taiwan); H.-W. Tsao, Y.-R. Huang, National Taiwan Univ. (Taiwan); S.-L. Lee, National Taiwan Univ. of Science and Technology (Taiwan); C.-C. Chang, National Taiwan Univ. (Taiwan); W.-C. Lin, H.-L. Tsay, Instrument Technology Research Ctr. (Taiwan); Y.-L. Wang, National Taiwan Univ. (Taiwan); P.-H. Huang, M.-Y. Hsu, C.-W. Hsu, Instrument Technology Research Ctr. (Taiwan); S.-C. Lin, Y.-J. Hung, Y.-L. Shiu, National Taiwan Univ. of Science and Technology (Taiwan); Y.-C. Hsiao, J.-Y. Chang, National Taiwan Univ. (Taiwan); D. P. Tsai, T.-M. Huang, Instrument Technology Research Ctr. (Taiwan); H.-T. Young, Y.-C. Liu, National Taiwan Univ. (Taiwan); C.-M. Chang, National Taiwan Univ. of Science and Technology (Taiwan); W.-C. Chiang, Instrument Technology Research Ctr. (Taiwan); J.-Y. Huang, Y.-H. Chen, National Taiwan Univ. (Taiwan)

883204 A quantum oblivious transfer protocol [8832-3]

A. Parakh, Univ. of Nebraska at Omaha (United States)

883205 A high-speed GaAs-based electro-optic modulator for polarization, intensity, and phase modulation [8832-4]

H. Kato, Kato and Associates Research Ltd. (Canada); J. D. Bull, Point Grey Research (Canada); B. C. Tsou, Consultant (Canada); N. A. F. Jaeger, Univ. of British Columbia (Canada)

883206 Numerical examination of acousto-optic Bragg interactions for profiled lightwaves using a transfer function formalism [8832-5]

M. R. Chatterjee, F. S. Almehmadi, Univ. of Dayton (United States)

INTERACTION/NON-INTERACTION OF WAVES

883207 Mechanism of photonic interaction [8832-6]

A. Meulenberg, Science for Humanity Trust, Inc. (United States) 
883208 A mechanism for wave interaction during interference [8832-7]

W. R. Hudgins, Science for Humanity Trust, Inc. (United States); A. Meulenberg, Science for Humanity Trust, Inc. (United States) and Science for Humanity Trust (India); R. F. Penland,

Science for Humanity Trust (India)

883209 Does the coherent lidar system corroborate non-interaction of waves (NIW)? [8832-8]

N. S. Prasad, NASA Langley Research Ctr. (United States); C. Roychoudhuri, Univ. of

Connecticut (United States)

8832 OA Understanding beam alignment in a coherent lidar system [8832-9]

N. S. Prasad, NASA Langley Research Ctr. (United States); C. Roychoudhuri, Univ. of

Connecticut (United States)

\section{PHOTON AND PHOTON MODELS I}

8832 OB The photon: issues of integrity (Invited Paper) [8832-10]

D. L. Andrews, Univ. of East Anglia Norwich (United Kingdom)

8832 OC Hidden variables: basically unfolded [8832-11]

E. H. Berloffa, Retired (Austria)

8832 OD Phat photons and phat lasers [8832-12]

P. E. Williams, Retired (United States)

8832 OE Photon statistics: math versus mysticism [8832-13]

A. F. Kracklaver, Consultant (Germany)

PHOTON AND PHOTON MODELS II

8832 OF New experiments and questions to shed light on the nature of a photon [8832-14]

C. F. Maes, Univ. of Arizona College of Optical Sciences (United States)

8832 OG Single-photon detection, truth, and misinterpretation [8832-15]

E. H. Berloffa, Leopold-Franzens-Univ. Innsbruck (Austria)

$8832 \mathrm{OH}$ The nature of the photon in the viewpoint of a generalized particle model (Invited Paper) [8832-16]

A. Giese, Consultant (Germany)

$8832 \mathrm{Ol}$ Consequences of partitioning the photon into its electrical and magnetic vectors upon absorption by an electron [8832-17]

D. S. Szumski, Independent Scholar (United States)

PHOTON AND PHOTON MODELS III

8832 OK The two body photon [8832-20]

R. T. Dorn, Consultant (United States)

iv 
$8832 \mathrm{OL}$ Further investigation of an integrated picture of photon diffraction described by virtual particle momentum exchange [8832-21]

M. J. Mobley, Grand Canyon Univ. (United States) and Arizona State Univ. (United States)

$88320 \mathrm{M}$ The photonic soliton [8832-22]

A. Meulenberg, HiPi Consulting (United States)

$8832 \mathrm{ON}$ The photon concept revisited: role of cooperative virtual processes in light harvesting [8832-23]

D. V. Voronine, Texas A\&M Univ. (United States) and Baylor Univ. (United States); A. Joshi, Texas A\&M Univ. (United States); P. Vetter, Texas A\&M Univ. (United States), Baylor Univ. (United States), and Princeton Univ. (United States)

883200 The problematic photon (Invited Paper) [8832-24]

A. I. Vistnes, Univ. of Oslo (Norway)

RELATIVITY, SPACE, AND PROPERTIES

8832 OP Subtlety in relativity (Invited Paper) [8832-25]

S. M. Wagh, Central India Research Institute (India)

$88320 Q \quad$ Spacetime-based model of EM radiation [8832-26]

J. A. Macken, Macken Instruments Inc. (United States)

8832 OR Can highly relativistic particles explain part of the dark Universe? [8832-27]

K. O. Greulich, Fritz Lipmann Institute (Germany)

8832 OT Resonant energy absorption and the CTF hypothesis [8832-29]

M. Ambroselli, C. Roychoudhuri, Univ. of Connecticut (United States)

8832 OU The influence of gravitation on electromagnetism (Invited Paper) [8832-63]

G. Zbiral, Consultant (Austria)

FOUNDATIONAL THINKING

8832 OW Emergent mechanics, quantum and un-quantum [8832-31]

J. P. Ralston, Univ. of Kansas (United States)

8832 OY Quantum indeterminism: a direct consequence of Fourier ontology (Invited Paper)

[8832-33]

J. R. Croca, Univ. de Lisboa (Portugal)

$8832 \mathrm{OZ}$ How would photons describe natural phenomena based upon their physical experiences? [8832-34]

C. Roychoudhuri, Univ. of Connecticut (United States) and Femto Marco Continuum (United States)

883210 The Mandelbrot set and the fractal nature of light, the Universe, and everything [8832-35]

L. Gardi, Consultant (Canada) 
FOUNDATION: QM AND PHYSICS I

883212 Quantum theory as the most robust description of reproducible experiments: application to a rigid linear rotator (Invited Paper) [8832-37]

H. De Raedt, Univ. of Groningen (Netherlands); M. I. Katsnelson, Radboud Univ.

(Netherlands); K. Michielsen, Forschungszentrum Jülich GmbH (Germany) and RWTH

Aachen Univ. (Germany)

883213 The Schrödinger description of a single photon [8832-38]

G. Shchedrin, Texas A\&M Univ. (United States) and Princeton Univ. (United States)

883214 The finite thermodynamic topology of photons [8832-39]

R. M. Kiehn, Univ. of Houston (United States)

883215 Quantum geometro-dynamics of photons, fermions and motive energy [8832-40]

V. Fernando, Consultant (Canada)

883216 Revising your world-view of the fundamental constants [8832-41]

J. P. Ralston, The Univ. of Kansas (United States)

FOUNDATION: QM AND PHYSICS II

883218 What is a particle? A lesson from the photon (Invited Paper) [8832-43]

K. O. Greulich, Fritz Lipmann Institute (Germany)

883219 The physical origins of the uncertainty theorem [8832-44]

A. Giese, Consulatnt (Germany)

$88321 \mathrm{~A}$ On the possibility of laser-assisted production and detection of low-energy neutrino beams [8832-45]

J. W. Eerkens, Prodev Consultants (United States) and Univ. of Missouri-Columbia (United States)

8832 1B Inadequacies in De Broglie's Theory: rectifications, verifications, and applications [8832-46]

H. Chauhan, R. K. Sinha, Delhi Technological Univ. (India)

FOUNDATION: QM AND PHYSICS III

8832 1C Higgs Boson: god particle or divine comedy? (Invited Paper) [8832-47]

C. Rangacharyulu, Univ. of Saskatchewan (Canada)

8832 1D Geometrical and quantum mechanical aspects in observers' mathematics [8832-48]

B. Khots, Compressor Controls Corp. (United States); D. Khots, Consultant (United States)

8832 1E Can one distinguish between Doppler shifts due to source-only and detector-only velocities? [8832-49]

C. Roychoudhuri, Univ. of Connecticut (United States) and Femto Macro Continuum

(United States); M. Ambroselli, Univ. of Connecticut (United States) 
8832 IF On reconciling quantum mechanics and local realism [8832-50]

D. A. Graft, Retired (United States)

EPR, BELL, DUALITY, AND ENTANGLEMENT I

8832 IG Wave-particle dualism unraveled by Young's double slit experiment (Invited Paper) [8832-51]

A. Hever, D. Puhlmann, R. Menzel, Univ. Potsdam (Germany)

883211 Entangled photons and antibunching phenomena revisited on the basis of various models for light [8832-53]

A. P. Thörn, Univ. of Oslo (Norway)

$88321 \mathrm{~J} \mathrm{Can} \mathrm{violations} \mathrm{of} \mathrm{Bell's} \mathrm{inequalities} \mathrm{be} \mathrm{considered} \mathrm{as} \mathrm{a} \mathrm{final} \mathrm{proof} \mathrm{of} \mathrm{quantum} \mathrm{physics?}$ [8832-54]

F. Hénault, Univ. Joseph Fourier (France)

$88321 \mathrm{~K}$ Observation of bosonic coalescence and fermionic anti-coalescence with indistinguishable photons [8832-55]

G. Adenier, J. Bergli, A. P. Thörn, A. I. Vistnes, Univ. of Oslo (Norway)

EPR, BELL, DUALITY, AND ENTANGLEMENT II

8832 1L Nonclassical effects in two-photon interference experiments: an event-by-event simulation [8832-57]

K. Michielsen, Forschungszentrum Jülich GmbH (Germany) and RWTH Aachen Univ. (Germany); F. Jin, Forschungszentrum Jülich GmbH (Germany); H. De Raedt, Univ. of Groningen (Netherlands)

$88321 \mathrm{M}$ Event-by-event simulation of experiments to create entanglement and violate Bell inequalities [8832-58]

K. Michielsen, Forschungszentrum Jülich GmbH (Germany) and RWTH Aachen Univ. (Germany); H. De Raedt, Univ. of Groningen (Netherlands)

8832 IN Data analysis of Einstein-Podolsky-Rosen-Bohm laboratory experiments [8832-59] H. De Raedt, Univ. of Groningen (Netherlands); F. Jin, Forschungszentrum Jülich GmbH (Germany); K. Michielsen, Forschungszentrum Jülich GmbH (Germany) and RWTH Aachen Univ. (Germany)

883210 A rational explanation of wave-particle duality of light (Invited Paper) [8832-60] S. A. Rashkovskiy, Institute for Problems in Mechanics (Russian Federation)

Author Index 
Proc. of SPIE Vol. $8832883201-8$

Downloaded From: https://www.spiedigitallibrary.org/conference-proceedings-of-spie on 26 Apr 2023 Terms of Use: https://www.spiedigitallibrary.org/terms-of-use 


\title{
Conference Committee
}

\author{
Conference Chairs
}

Chandrasekhar Roychoudhuri, University of Connecticut (United States) and Femto Macro Continuum (United States)

Al F. Kracklauer, Consultant (Germany)

Hans De Raedt, University of Groningen (Netherlands)

Conference Program Committee

David L. Andrews, University of East Anglia (United Kingdom)

Benjamin J. Eggleton, The University of Sydney (Australia)

Tepper L. Gill, Howard University (United States)

Karl Otto Greulich, Fritz Lipmann Institute (Germany)

Manuel Fernández-Guasti, Universidad Autónoma Metropolitana-

Iztapalapa (Mexico)

Habib Hamam, University de Moncton (Canada)

François Hénault, Laboratoire d'Astrophysique de l'Observatoire de Grenoble (France)

Subhash C. Kak, Oklahoma State University (United States)

Andrei Yu. Khrennikov, Linnaeus University (Sweden)

Akhlesh Lakhtakia, The Pennsylvania State University (United States)

Carl F. Maes, College of Optical Sciences, The University of Arizona (United States)

Andrew Meulenberg Jr., University Sains Malaysia (Malaysia) and Hi Pi Consulting (United States)

Kristel F. Michielsen, Forschungszentrum Jülich GmbH (Germany)

John M. Myers, Harvard University (United States)

Narasimha S. Prasad, NASA Langley Research Center (United States)

Chary Rangacharyulu, University of Saskatchewan (Canada)

William T. Rhodes, Florida Atlantic University (United States)

Wolfgang P. Schleich, Universität Ulm (Germany)

Marlan O. Scully, Texas A\&M University (United States) and Princeton University (United States)

Weilong She, Sun Yat-Sen University (China)

Riccardo C. Storti, Delta Group Engineering, P/L (Australia)

Arnt Inge Vistnes, University of Oslo (Norway)

Ewan Malcolm Wright, College of Optical Sciences, The University of Arizona (United States)

Session Chairs

1 Experiments and Optical Technologies

Al F. Kracklaver, Consultant (Germany)

Hans De Raedt, University of Groningen (Netherlands) 
2 Interaction/Non-interaction of Waves

Narasimha S. Prasad, NASA Langley Research Center (United States)

Andrew Meulenberg Jr. University Sains Malaysia (Malaysia) and $\mathrm{Hi} \mathrm{Pi}$ Consulting (United States)

3 Photon and Photon Models I

Chandrasekhar Roychoudhuri, University of Connecticut (United States)

Al F. Kracklaver, Consultant (Germany)

4 Photon and Photon Models II

Carl F. Maes, College of Optical Sciences, The University of Arizona (United States)

Erich H. Berloffa, Leopold-Franzens-Univ. Innsbruck (Austria)

5 Photon and Photon Models III

Andrew Meulenberg Jr., University Sains Malaysia (Malaysia) and $\mathrm{Hi} \mathrm{Pi}$ Consulting (United States)

Michael J. Mobley, Arizona State University (United States)

6 Relativity, Space, and Properties

Al F. Kracklauer, Consultant (Germany)

Karl Otto Greulich, Fritz Lipmann Institute (Germany)

7 Foundational Thinking

Lori Gardi, Robarts Research Institute (Canada)

8 Foundation: QM and Physics I

John Ralston, The University of Kansas (United States)

Dawei Wang, Texas A\&M University (United States)

9 Foundation: QM and Physics II

Karl Otto Greulich, Fritz Lipmann Institute (Germany)

Albrecht Giese, Deutsches Elektronen-Synchrotron (Germany)

10 Foundation: QM and Physics III

Boris Khots, Compressor Controls Corporation (United States)

Chandrasekhar Roychoudhuri, University of Connecticut (United States)

11 EPR, Bell, Duality, and Entanglement I

François F. Hénault, Laboratoire d'Astrophysique de l'Observatoire de Grenoble (France)

Arkady Plotnitsky, Purdue University (United States)

12 EPR, Bell, Duality, and Entanglement II

Kristel F. Michielsen, Forschungszentrum Jülich GmbH (Germany)

Hans De Raedt, University of Groningen (Netherlands) 


\section{Introduction}

First, we must thank our committee members and all the authors for their time and effort to make this fifth biennial conference a great success. It is the active efforts of many members in seeking out new valuable contributors, which is adding further quality and the recognition of this "special" conference through its sustained growth. Of course, we must also thank all the SPIE staff, whose tireless professional services are of critical importance: for getting everything done correctly and on time, in spite of the constant pulls by innumerable authors and chairs, demanding innumerable actions "immediately!"

Before highlighting this year's conference (Section-3); let us briefly present the plan for our sixth biennial conference to be held in August of 2015, at San Diego. The year 2015 has also been declared as the celebration of "Year of Light" by the Executive Board of UNESCO [http://www.prweb.com/releases/2012/10/prweb10054327.htm]. We welcome this declaration and we will play our part by promoting a deeper understanding of the nature of light that overcomes the philosophical and cultural prejudices that are holding back enlightened thinking and consequent progress in physics and the society, at large. Those who are interested in developing web-based dialogues with their colleagues and highlight their own epistemology; are welcomed to utilize the website: http://www.natureoflight.org/. Here, the video of Prof. Carver Mead's talk, given at our fifth biennial conference, can be viewed.

\section{Call for the sixth biennial conference}

While we have stayed on course with the ontological question "What are photons?" we are actively soliciting participation from all major fields of physics (classical optics, quantum optics, relativity, cosmology, etc.) from the standpoint of foundational thinking. The two worlds of electromagnetism and material particles are inseparably intertwined: This is quite obvious from the electronpositron pair production out of gamma rays and production of gamma rays from electron-positron collision. The expression wave-particle-duality and the related debate started some 400 years ago with Newton and Huygens; when this expression was understood as lack of our understanding and required raising deeper questions. Instead, over the last hundred years, our prevailing scientific culture succeeded in elevating this lack of knowledge as a new knowledge! That is why the importance of this conference forum is timely and is growing and thriving.

The significance of this forum also derives from historic pragmatic reality. Optical science and engineering have been providing us with the key enabling tools (both incisive thinking and precision measuring instruments) in advancing broader science and technologies since ancient times. For this next conference, we would like to explicitly call out for submissions in the broad domains of frequency and 
time, concepts and measurements. The importance of explicitly calling out this sub-field could be valuable in the experimental world since we measure frequency, not the running time.

\title{
2. Brief history behind this conference series.
}

This "special" conference started on the opportune year of 2005 when the whole world was celebrating the centennial celebration of the "Einstein's Miracle Year"! We have just finished the fifth biennial conference and have started planning for the sixth biennial conference to be held during August of 2015; All of you and your very welcomed to participate. Please, start soliciting your colleagues to join us in 2015. In this year of 2013, we have had 64 accepted papers and we are publishing 52. Ten of the accepted papers could not be published so we can adhere to in-person presentation requirement of SPIE. The main issue was due mostly to visa problems and a few of them were due to last-minute withdrawals for various personal reasons. In 2011 , we published 56 out of 63 accepted papers. In 2009, we published 31 papers. In 2007, we published 31 papers. In 2005, we published 34 papers. From the sustained improvements in the quality and the quantity of papers indicate that we definitely are serving an important need for our scientific and engineering community. Basic science and engineering are inseparable.

\section{Brief summary of the content in this volume.}

The readers will find the papers in this volume grouped according the following topics, which were used to broadly categorize various submitted papers:

\author{
Session 1: $\quad$ Experiments and Optical Technologies \\ Session 2: $\quad$ Interaction/Non-interaction of Waves \\ Session 3, 4, 5: $\quad$ Photon and Photon Models I, II \& III \\ Session 6: $\quad$ Relativity, Space, and Properties \\ Session 7: $\quad$ Foundational Thinking \\ Technical Event: The Nature of Light: What are Photons \\ Session 8, 9, 10: Foundation: QM and Physics I, II, III. \\ Session 11, 12: EPR, Bell, Duality, and Entanglement I, II. \\ Workshop and Discussion: on The Nature of Light: What are Photons?
}

This year, our traditional effort behind the discussion and debate at the end of the meeting was not well organized: We apologize for that. We will do better in 2015. You are welcome to promote topics for such discussions.

One of the major highlights of this fifth biennial conference was the Keynote Speech by famous Caltech Professor, Carver Mead, who is a winner of US Presidential Medal of Science. Mead is most well known as the father of VLSI, which is behind the rapid growth of computer and information technologies by virtue of steady miniaturization of computer chips (doubling of the transistor density in every two years). Mead's path breaking out-of-box scientific thinking can be appreciated from his book, Collective Electrodynamics. The summary of 
Mead's excellent talk on his views, about the current physics thinking and the nature of photons, has been designated in this volume as 883202 (8832-100).

For all those who are looking for a rational approach to understand EM waves, beyond antiquated "light quanta," will find this volume a "breath of fresh air"not because we have solved all the problems but because it provides us with a wide variety of novel and yet logical approaches to understand what photons and particles could be. Some of the papers describe both photons and particles as harmonics oscillations, which eliminate the need for wave-particle duality. It comes out loud and clear through another set of papers that photoelectron counting statistics do not establish photons as "indivisible quanta," especially since electrons are discrete particles, and they are always bound to atoms and materials with discrete energy levels, which must be stimulated as dipoles with resonant optical frequencies. Other papers underscore that careful analysis of EPRB experiments does not validate that QM is the final/complete theory of the micro universe. A few other papers lead us to appreciate that there is not a gulf of difference between quantum mechanics (mathematics) and classical mechanics (mathematics), as has previously been made out by the Copenhagen Interpretation of QM. After all, classical biological bodies are continuously functioning and evolving by virtue of quantum mechanical interactions between biological molecules. Some papers underscore that one of the root problem behind the emergence of non-causality in physics is not due to inherent property of nature; but because we use the non-causal Fourier Theorem as a key mathematical tool. First, Fourier modes, existing over all space and time, violate conservation of energy. Second, propagating waves, in the linear domain, do not sum themselves to reorganize their energy distribution in the absence of interacting materials (dipoles). Others have presented the argument that the Uncertainty Principle is really not a principle of nature; it is rather an outcome of our mathematical logics like the Fourier Theorem. Several papers also challenge the fundamental hypotheses behind Relativity and Gravitation. One paper draws our attention that even the historical origin and the physical meanings of the various fundamental constants require serious review. Another paper underscores that Doppler effects for material based waves and EM waves are not different; which has profound implications in understanding the physical processes behind measured Hubble red shifts.

The foundation of the edifice of physics has not been finalized. Our future generations have plenty to investigate and discover. Let us create the right platform so their enquiring minds can keep on flourishing!

Chandrasekhar Roychoudhuri Al F. Kracklauer Hans De Raedt 
Proc. of SPIE Vol. $8832883201-14$

Downloaded From: https://www.spiedigitallibrary.org/conference-proceedings-of-spie on 26 Apr 2023 Terms of Use: https://www.spiedigitallibrary.org/terms-of-use 